REVISÃO

\title{
CARNES DE HAMBÚRGUERES
}

PRONTAS PARA CONSUMO:

ASPECTOS LEGAIS E RISCOS BACTERIANOS

Talissa de Moraes Tavares ${ }^{1}$ e Álvaro Bisol Serafini ${ }^{2}$

\section{RESUMO}

\begin{abstract}
A presente revisão descreve os aspectos básicos necessários para assegurar a qualidade higiênicosanitária de carnes de origem bovina, mais especificamente sobre o hambúrguer pronto para o consumo, que é atualmente um dos alimentos produzidos em grande escala e de crescente consumo no Brasil. Os limites e padrões microbiológicos que devem ser adotados para garantir uma correta interpretação sobre os resultados das análises microbiológicas, os fatores que contribuem para a ocorrência de surtos de enfermidades de origem alimentar e a necessidade da implantação de sistemas de boas práticas de produção que visem identificar os perigos e os riscos microbiológicos são parâmetros importantes abordados ao longo deste trabalho. Além disso, são descritos os aspectos legais e os perigos bacterianos que comprometem a qualidade destes alimentos expostos à venda ou ao consumo, visando-se, sobretudo, prevenir ou minimizar o número de doenças veiculadas por alimentos, visto que estas representam um dos problemas de saúde pública mais difundidos no contexto mundial.
\end{abstract}

DESCRITORES: Hambúrgueres. Microrganismos. Enfermidades transmitidas por alimentos.

\section{INTRODUÇÃO}

Aqualidade dacarne destinada ao consumoémotivo de constante preocupação em todo o mundo, em especial no Brasil, país considerado o maior produtor mundial de carne bovina (Anualpec, 2003) e onde o consumo per capita de carne e derivados é de $36 \mathrm{~kg} /$ ano (Prado et al., 2004). Segundo o Instituto de Tecnologia de Alimentos (ITAL), a carne bovina de segunda é a mais consumida, principalmente pelas classes com renda salarial menor que dez salários mínimos (Garcia \& Bliska, 2000).

1 Biomédica, MSc, aluna de Doutorado do Programa de Pós-Graduação em Medicina Tropical do Instituto de Patologia Tropical e Saúde Pública da Universidade Federal de Goiás.

2 Prof. Titular do Departamento de Microbiologia, Imunologia, Parasitologia e Patologia do Instituto de Patologia Tropical e Saúde Pública da Universidade Federal de Goiás.

Endereço para correspondência: Rua Delenda Rezende de Melo, esq. com $1^{\mathrm{a}}$ Avenida, Setor Universitário, Cx. Postal 131, CEP: 74605-050, Goiânia, Goiás, Brasil. E-mail: abisol@iptsp.ufg.br

Recebido para publicação em 28/5/2004. Revisto em 5/8/2005. Aceito em 23/3/2006. 
Nos últimos anos, os hábitos alimentares da população sofreram alterações motivadas especialmente pelos processos de urbanização, industrialização, profissionalização das mulheres e diminuição do tempo disponível para a preparação de alimentos e/ou para o seu consumo. Esse contexto tem favorecido substancialmente o consumo de produtos industrializados ou preparados fora do domicílio (Lima \& Oliveira, 2005; Fattori et al., 2005).

A necessidade de se buscar refeições fora de casa, prontas para o consumo, produzidas em grande escala e que fossem rápidas e baratas como os hambúrgueres de carne bovina, tornou opção crescente entre a população as sanduicherias ou lanchonetes do tipo trailers localizados em ruas, praças e lotes públicos, assim como as redes de restaurantes fast food (Levrè et al., 2000; Tavares \& Serafini, 2003; Lima \& Oliveira, 2005; Fattori et al., 2005).

Estes produtos, que nem sempre são legalmente regulamentados e submetidos a procedimentos de fiscalização, têm contribuído para elevar consideravelmente a freqüência de toxinfecções alimentares em nível mundial (Germano et al., 2000; OMS, 2002; Fattori et al., 2005). Tal situação resulta em prejuízos econômicos na ordem de até 6,5 bilhões de dólares anuais para os Estados Unidos da América, EUA(U.S. General Accounting Office - GAO, 2001).

Também nos EUA, país onde 9\% dos habitantes consomem diariamente hambúrgueres (Walls \& Scott, 1997), foi constatado que grande parte das doenças é resultante do consumo destes alimentos mal cozidos ou da adoção de práticas inadequadas na preparação (Shiferaw et al., 2000; Patil et al., 2005).

O hambúrguer é um produto cárneo industrializado, obtido da carne moída de animais de açougue, com adição ou não de tecido adiposo e outros ingredientes (Brasil, 2000). Este produto é submetido a um processo de manipulação excessiva com problemático sistema de conservação, o que favorece a instalação e a veiculação de patógenos. Considerando-se tais características, tornam-se necessárias a avaliação de sua qualidade higiênico-sanitária do ponto de vista microbiológico e a adoção de práticas adequadas para sua conservação e preparação a fim de garantir que o consumo ocorra de forma segura e livre de contaminação (Levrè et al., 2000; Tavares \& Serafini, 2003; Lima \& Oliveira, 2005).

\section{ASPECTOS MICROBIOLÓGICOS DO CONTROLE DE QUALIDADE}

A Resolução RDC no 12 da Agência Nacional de Vigilância Sanitária do Ministério da Saúde (ANVISA/MS) estabeleceu o Regulamento Técnico sobre Padrões Microbiológicos para Alimentos Destinados ao Consumo Humano e recomenda metodologias analíticas como as dispostas no Codex Alimentarius, Internacional Commission on Microbiological Specifications for Foods (ICMSF), American Public Health Associaton (APHA) ou Food and Drug Administration (FDA), ou ainda outras metodologias internacionalmente reconhecidas (Brasil, 2001a). 
Os alimentos são qualificados como próprios ou impróprios ao consumo humano de acordo com critérios microbiológicos que são estabelecidos pela legislação de cada país ou definidos, em nível internacional, pelo Codex Alimentarius e pelos programas Food and Agriculture Organization e World Health Organization (FAO/WHO) (Munuera et al., 1997; Schlundt, 2002; Jay, 2005).

Os critérios para o estabelecimento de padrões microbiológicos em alimentos envolvem: os grupos de microrganismos ou suas toxinas consideradas de interesse sanitário, a classificação de alimentos segundo o risco epidemiológico, os métodos de análise que permitam a determinação e a quantificação dos microrganismos e o plano de amostragem (Brasil, 2001a; Jay, 2005).

Essas normas devem basear-se no conhecimento da ecologia microbiana para que sejam estabelecidos os limites de tolerância ou valores máximos admissíveis para cada produto. A análise microbiológica é que vai determinar se o produto está ou não adequado dos pontos de vista higiênico-sanitário e de saúde pública (Munuera et al., 1997; Tauxe, 2002).

As carnes e seus derivados constituem veículo potencial de contaminantes de natureza biológica, física ou química nas diversas fases de seu processamento, desde sua origem ou produção primária até as fases de transformação, armazenagem, transporte e distribuição para o consumo (Feitosa, 1999; Silva et al., 2004).

Na legislação vigente (Brasil, 2001a), as amostras de pratos prontos para o consumo humano, à base de carne, devem ser interpretadas, de acordo com as especificações, como produtos em condições sanitárias satisfatórias ou insatisfatórias. Nesta legislação não existem padrões microbiológicos específicos para hambúrgueres cozidos; adotam-se, portanto, os padrões para pratos cárneos prontos para o consumo (Tabela 1).

Tabela 1. Padrões microbiológicos para pratos cárneos prontos para o consumo de acordo com a Resolução RDC nº12/2001 da ANVISA/MS

\begin{tabular}{|c|c|c|c|c|c|}
\hline \multirow[t]{2}{*}{ Microrganismos } & \multirow{2}{*}{$\begin{array}{c}\text { Tolerância } \\
\text { para amostra } \\
\text { Indicativa }^{\mathrm{a}}\end{array}$} & \multicolumn{4}{|c|}{$\begin{array}{l}\text { Tolerância para amostra } \\
\text { Representativa }^{\mathrm{b}}\end{array}$} \\
\hline & & $\mathrm{N}^{1}$ & $\mathrm{C}^{2}$ & $\mathrm{~m}^{3}$ & $\mathrm{M}^{4}$ \\
\hline Contagem de Coliformes a $45^{\circ} \mathrm{C} / \mathrm{g}$ & $2 \times 10$ & 5 & 2 & 10 & $2 \times 10$ \\
\hline Contagem de Staphylococcus coagulase positiva/g & $10^{3}$ & 5 & 2 & $5 \times 10^{2}$ & $10^{3}$ \\
\hline Contagem de Bacillus cereus/g & $10^{3}$ & 5 & 2 & $5 \times 10^{2}$ & $10^{3}$ \\
\hline Contagem de Clostridium sulfito redutor a $460 \mathrm{C} / \mathrm{g}$ & $10^{3}$ & 5 & 2 & $5 \times 10^{2}$ & $10^{3}$ \\
\hline Pesquisa de Salmonella $\mathrm{sp} / 25 \mathrm{~g}$ & - & 5 & 0 & - & - \\
\hline $\begin{array}{l}\text { a: amostra indicativa-composta por um número de } \\
\text { de amostragem constante na legislação específica. } \\
\text { b: amostra representativa - constituída pelo número } \\
\text { o plano de amostragem. } \\
\text { 1: } \mathrm{n} \text { - é o número de unidades a serem colhida } \\
\text { individualmente. } \\
\text { 2: c - é o número máximo aceitável de unidades de } \\
\text { 3: } \mathrm{m} \text { - limite inferior estabelecido pela legislação. } \\
\text { 4: } \mathrm{M} \text { - limite superior estabelecido pela legislação. }\end{array}$ & $\begin{array}{l}\text { unidades amos } \\
\text { o de unidades a } \\
\text { as aleatoriamen } \\
\text { amostras com }\end{array}$ & astrai & $\begin{array}{l}\text { or aoc } \\
\text { stabel } \\
\text { mesn }\end{array}$ & $\begin{array}{l}\text { abelecide } \\
\text { do de ac } \\
\text { lote e a } \\
\text { limites } \mathrm{d}\end{array}$ & $\begin{array}{l}\text { no plano } \\
\text { rdo com } \\
\text { alisadas } \\
\text { m e M. }\end{array}$ \\
\hline
\end{tabular}


São exigidos outros critérios na produção de hambúrguer de carne bovina, segundo os quais a matéria-prima utilizada deve obedecer aos processos de inspeção prescritos no Decreto no 30.691 (Brasil, 1952). Para a rotulagem, aplica-se o Regulamento Técnico para Rotulagem de Alimentos Embalados da Portaria $\mathrm{n}^{\circ} 371$ (Brasil, 1997b) e para a fabricação, as práticas de higiene de acordo com o Código Internacional de Práticas de Higiene para Produtos Cárneos Elaborados (WHO, 1985). As indústrias devem seguir o Regulamento Técnico sobre as Condições Higiênico-Sanitárias e de Práticas de Elaboração para Estabelecimentos Elaboradores e ou Industrializadores de Alimentos da Portaria nº 368 (Brasil, 1997a).

\section{MICRORGANISMOS CONTAMINANTES}

Os microrganismos que contaminam os produtos cárneos são amplamente distribuídos na natureza e podem ser encontrados na água, no ar, no solo, no trato intestinal do homem e de animais, na pele, nas mãos e no trato respiratório dos manipuladores de alimentos, na pele e nas carcaças de bovinos e nos utensílios e equipamentos de abatedores e de cozinhas (Elder et al., 2000; Martins et al., 2001; Jo et al., 2004; Fattori et al., 2004; Jay, 2005).

A microbiota normal de produtos à base de carne bovina moída sob condições higiênicas é composta, predominantemente, por bactérias Gram-negativas da família Enterobacteriaceae e do gênero Pseudomonas e por Gram-positivas dos gêneros Enterococcus, Lactobacillus e Staphylococcus (Jay, 2005). As bactérias patogênicas ou potencialmente mais comuns nestes alimentos são Escherichia coli, Clostridium perfringens, S. aureus e Salmonella, e, ocasionalmente, Yersinia enterocolitica, Clostridium botulinum e Bacillus cereus (Lindqvist et al., 2001; Zansky et al., 2002; Silva et al., 2004; Fortuna \& Franco, 2005; Jay, 2005).

Alguns microrganismos, como E. coli O157:H7 e Salmonella spp, são mais freqüentemente isolados em hambúrgueres contaminados implicados em surtos infecciosos de origem alimentar (Haeghebaer et al., 2001; Zansky et al., 2002; Rivas et al., 2003; Rangel et al., 2005).

\section{MICRORGANISMOS PATOGÊNICOS GRAM - NEGATIVOS}

Salmonella sp. São bastonetes Gram-negativos, pertencentes à família Enterobacteriaceae, normalmente patogênicas e podem estar presentes em fezes de animais e portadores humanos. Foram descritos mais de 2.200 sorotipos, sendo $S$. typhimurium e $S$. enteritidis os de maior freqüência em amostras clínicas. A partir de 1991, foi observado um aumento gradual dos isolados de $S$. enteritidis associado ao consumo de alimentos contaminados (Cogco et al., 2000; Koneman et al., 2001). Apesar de a carne bovina ser veículo transmissor destas bactérias, esta não representa a principal fonte de disseminação, e sim, os produtos de origem avícola e suína (Bessa et al., 2004; Jay, 2005). Concentrações em torno de $10^{7}$ a $10^{9}$ células/g 
de alimentos são necessárias para que ocorra uma salmonelose, embora a ingestão de alimentos com pelo menos 15 a 20 células possa causar infecção, dependendo da idade e da imunidade do indivíduo (FDA, 2005b; Jay, 2005).

Escherichia coli. São bastonetes Gram-negativos, também da família Enterobacteriaceae. Fazem parte da microbiota intestinal do homem e animais e sua presença em alimentos é indicativa de contaminação fecal (Koneman et al., 2001; Jay, 2005). As doenças diarréicas causadas por grupos de E. coli, como enteropatogênica (EPEC), enterotoxigênica (ETEC), enterohemorrágica (EHEC), enteroinvasiva (EIEC), enteroagregativa (EaggEC) e difusamente aderida (DAEC) são comuns no mundo inteiro e manifestam-se através de diferentes mecanismos, de acordo com as propriedades de virulência de cada grupo (Nataro \& Kaper, 1998; Koneman et al., 2001). A carne bovina de hambúrguer é considerada o principal veículo de $E$. coli O157:H7, uma vez que os bovinos são os reservatórios mais comuns (Callaway et al., 2003; Rangel et al., 2005). A ingestão de alimentos com contagem menor que 10 organismos/g é suficiente para causar infecção (FDA, 2005a).

Yersinia enterocolitica e Klebsiella sp. São enterobactérias Gramnegativas geralmente encontradas em alimentos cárneos ou após o contato destes com material fecal, água ou utensílios contaminados. A Y. enterocolitica foi evidenciada em carnes de origem bovina e suína e com grande freqüência em produtos cárneos embalados a vácuo (CDC, 2004b; Jay, 2005). Dentre as espécies de Klebsiella, a K. pneumoniae enteroinvasiva foi isolada, no final dos anos 1990, de hambúrguer servido por uma cadeia de restaurantes fast food nos EUA, tendo causado gastrenterite e sepse (Sabota et al., 1998).

\section{MICRORGANISMOS PATOGÊNICOS GRAM-POSITIVOS}

Staphylococcus sp. são membros da microbiota da pele e das mucosas de seres humanos, sendo o $S$. aureus produtor de toxinas termoestáveis, responsáveis por toxinoses alimentares (Koneman et al., 2001; Le Loir et al., 2003). São reconhecidos 14 tipos de enterotoxinas (A, B, C1, D, E, G, H, I, J, K, L, M, N, O), dos quais os tipos A, B e C foram identificados em amostras de hambúrgueres (Jarraud et al., 2001; Soriano et al., 2002; Le Loir et al., 2003). A toxinose alimentar por S. aureus requer a ingestão acima de $10^{5} \mathrm{organismos} / \mathrm{g}$ de alimento e/ou de $1 \mu \mathrm{g}$ de toxina/g de alimento para se iniciarem os sintomas clínicos, incluindo náusea, vômito, espasmo abdominal e, ocasionalmente, diarréia. A duração dos sintomas é curta, variando de 30 minutos a 8 horas, entretanto, para recém-nascidos e indivíduos idosos, a doença pode ser fatal (Le Loir et al., 2003; FDA, 2005c).

Bacillus sp. São bastonetes Gram-positivos, formadores de esporos e comuns no solo, na água, no ar e na vegetação (Koneman et al., 2001). O B. cereus 
é a espécie mais isolada e pode causar toxinose alimentar com duas formas clínicas distintas: a emética e a diarréica. A forma emética tem período de incubação de uma a seis horas, manifesta-se por náusea, vômitos, cólica abdominal e, às vezes, diarréia. Está associada a pratos à base de arroz, quentes ou frios, contendo $2 \times 10^{9}$ organismos/g de alimento. A forma diarréica desenvolve sintomas como náuseas, cólicas abdominais e diarréia aquosa, comumente de 6 a 12 horas, e tem como principais veículos os pratos cárneos de origem aviária e bovina, preparados com carne moída, cozida e com molhos. Apresenta contagens em placas variando entre $10^{5}$ e $10^{8} \mathrm{UFG} / \mathrm{g}$ de alimento (Jay, 2005; Schoeni \& Wong, 2005).

Clostridium sp. São bastonetes anaeróbios moderados, Gram-positivos, formadores de esporos e estão amplamente distribuídos na natureza, sendo encontrados no solo e no trato intestinal de animal e seres humanos (Koneman et al., 2001). O C. perfringens tipo A produz uma enterotoxina, sobretudo em produtos cárneos moídos e cozidos. Após a ingestão de um número entre $10^{8}$ e $10^{9}$ de formas vegetativas, formam-se esporos no intestino e em seguida a enterotoxina, que provoca diarréia intensa em um prazo de 6 a 24 horas (Wen \& McClane, 2004; Fortuna \& Franco, 2005). O C. botulinum forma esporos termorresistentes e é responsável pelo botulismo, que é causado pela ingestão de alimentos contendo neurotoxinas pré-formadas dos tipos A, B, E, F ou G. O hambúrguer bovino contaminado por toxinas do tipo A foi identificado como veículo transmissor de botulismo. Esta doença neuroparalítica pode evoluir para óbito caso ocorra paralisia respiratória (Sobel et al., 2004; Jay, 2005).

\section{MICRORGANISMOS DETERIORANTES}

A deterioração de carnes é resultado da atividade metabólica de microrganismos presentes que podem causar alterações físicas, químicas ou sensoriais, isto é, alterações na cor, odor, textura, sabor ou aspecto desses alimentos (Forsythe, 2002).

Na carne moída ou na carne de hambúrguer bovina são evidenciadas, predominantemente, as bactérias deteriorantes aeróbias Gram-negativas como Pseudomonas, Alcaligenes, Acinetobacter, Moraxella e Aeromonas, que crescem na superfície desses alimentos e, ocasionalmente, as anaeróbias Gram-positivas como Lactobacillus, que se desenvolvem no interior (Forsythe, 2002, Jay, 2005). As Pseudomonas e Acinetocter-Moraxella spp são geralmente responsáveis pela deterioração primária, com algumas outras atuando em menor escala no processo (Jay, 2005).

As bactérias $P$ seudomonas e outras aeróbias Gram-negativas normalmente deterioram os produtos cárneos durante a estocagem a frio. As bactérias ácido-láticas causam deteriorações típicas em carnes estocadas em embalagens com atmosfera modificada ou embalagens a vácuo (Forsythe, 2002). 
Acinectobacter sp são normalmente comensais, juntamente com Pseudomonas são amplamente distribuídos no solo e água e ocasionalmente podem causar doenças em humanos, principalmente em pacientes imunodeprimidos. Alcaligenes sp fazem parte da microbiota normal humana, mas já foram isolados em respiradores, nebulizadores e em sistemas de diálise renal como patógenos oportunistas. Moraxella sp são membros da microbiota normal das vias aéreas superiores e, em algumas ocasiões, podem produzir infecções sistêmicas. Aeromonas sp têm como habitat natural a água doce ou do mar, podendo ser ainda encontradas em esgotos e em depósitos de água destilada, que são potenciais fontes de microrganismos envolvidos em infecções nosocomiais. Lactobacillus sp são ubíquos no ser humano e não patogênicos, podendo ser encontrados na boca, no intestino, na vagina e em outros sítios (Koneman et al., 2001).

\section{ENFERMIDADES TRANSMITIDAS POR ALIMENTOS}

As enfermidades transmitidas por alimentos (ETAs) são definidas como qualquer doença resultante da ingestão de alimentos contaminados. Podem ser causadas pelo consumo de produtos contendo células vegetativas viáveis de um agente infeccioso específico ou toxinas pré-formadas resultantes da proliferação de patógenos toxigênicos (Brasil, 2001a; WHO, 2002).

Essas enfermidades são consideradas pela OMS como um dos problemas de saúde pública mais difundidos no mundo contemporâneo e afetam até 30\% da população do mundo industrializado (WHO, 2002). As conseqüências que essas doenças podem causar à saúde humana são bastante variáveis, dependendo de sua natureza, estágio de tratamento, idade, susceptibilidade individual, patogenicidade do agente e número de organismos ingeridos (Buzby, 2002; Unnevehr et al., 2004).

Normalmente, os episódios agudos são brandos, autolimitados e de curta duração. Destacam-se como sintomas mais comuns: diarréia, cólica, dor abdominal, náusea e, raramente, vômito e febre (Buzby, 2002; Schlundt, 2002; Taege, 2004).

Algumas dessas doenças podem causar seqüelas graves e crônicas para os sistemas cardiovascular, renal, digestivo, respiratório ou imune, como a artrite reativa, nas infecções por Salmonella sp, a síndrome urêmica hemolítica, caracterizada por falência renal aguda por $E$. coli $\mathrm{O} 157: \mathrm{H} 7 \mathrm{e}$ as doenças intestinais necrotizantes por C. perfringens (Schlundt, 2002; Rivas et al., 2003; Taege, 2004; Sobel et al., 2005).

Crianças, idosos, gestantes e indivíduos imunodebilitados são considerados grupos de risco, uma vez que apresentam o sistema imunológico incompleto ou deficiente e, nestes casos, a ingestão de pequeno número de patógenos pode ser suficiente para causar doença. Deve-se considerar ainda que estas patologias podem manifestar-se de forma mais acentuada, causando sérias complicações ou até mesmo a morte (Buzby, 2002; McCabe-Sellers \& Beattie, 2004; Unnevehr et al., 2004).

Nas últimas décadas, foram identificadas novas espécies de patógenos ou verificado o reaparecimento de agentes já conhecidos e também foram 
desenvolvidos métodos mais eficazes de isolamento e detecção (Tauxe, 2002; Unnevehr et al., 2004). Mudanças demográficas e alterações nos hábitos alimentares têm provocado modificações tecnológicas na indústria com relação à formulação, ao processamento e à distribuição dos alimentos. Essas modificações, associadas à habilidade dos microrganismos de se desenvolverem rapidamente e se adaptarem ao ambiente, têm acarretado novos desafios ao sistema alimentar (Kasowski et al., 2002; WHO, 2002; Unnevehr et al., 2004).

A variedade de alimentos associados a surtos de doenças por eles veiculadas inclui os produtos de origem animal, como carnes vermelhas, de frango, peixes e frutos do mar, ovos, leite e seus derivados e os de origem vegetal, como as frutas e hortaliças (WHO, 2002; Taege, 2004; Adak et al., 2005). A carne bovina e seus derivados têm sido apontados como os principais veículos em vários surtos notificados em diferentes países (Lindqvist et al., 2001; Haeghebaert et al., 2001; Rivas et al., 2003; Adak et al., 2005; Rangel et al., 2005).

\section{FATORESQUECONTRIBUEMPARAAOCORRÊNCIADEENFERMIDADES TRANSMITIDAS POR ALIMENTOS}

Vários fatores contribuem para a ocorrência de ETAs: resfriamento inadequado, grande intervalo de tempo entre o preparo e o consumo, manipuladores infectados (sintomáticos ou não), processamento térmico inadequado, falhas no reaquecimento, contaminação cruzada, higienização deficiente de equipamentos e utensílios e obtenção de alimentos de fontes não seguras (Buzby, 2002; Silva Jr., 2002; Adak et al., 2005; Bernardi et al., 2005; Fattori et al., 2005; Lima \& Oliveira, 2005; Patil et al., 2005).

A multiplicação de patógenos nos produtos cárneos pode ocorrer em qualquer etapa da produção e do consumo e depende de fatores intrínsecos como atividade da água, $\mathrm{pH}$, potencial de óxido-redução, composição química, fatores antimicrobianos naturais, interações entre os microrganismos e de fatores extrínsecos relacionados com o ambiente como a umidade e a temperatura (Chesca et al.; 2001; Silva Jr., 2002; Jay, 2005).

A contaminação da carne bovina por bactérias de origem fecal pode ocorrer durante ou após o abate, no seu empacotamento ou ainda pela contaminação cruzada com bactérias encontradas no ambiente, superfícies, utensílios e equipamentos (Elder et al., 2000; Omisakin et al., 2003; Picchi, 2004). Posteriormente, no processo de moagem, microrganismos presentes na superfície das carnes são misturados com as demais porções, tornando o produto contaminado (Bergman et al., 2001; Jay, 2005).

Durante a produção do hambúrguer, tanto em estabelecimentos industriais e varejistas quanto na fabricação caseira, pode ocorrer contaminação resultante da adoção de práticas inadequadas de higiene ou após adição de condimentos ou outros ingredientes contaminados (Rivas et al., 2003; Stampi et al., 2004; Patil et al., 2005; Jay, 2005). Entretanto, a remoção ou a diminuição do número de bactérias coliformes pode 
ser evidenciada após o tratamento da carne utilizada na fabricação de hambúrgueres por pasteurização com água a $85^{\circ} \mathrm{C}$ por 45 ou 60 segundos (Gill et al., 2001).

$\mathrm{O}$ armazenamento e o resfriamento inadequados da carne também são fatores que contribuem para a ocorrência de ETAs (Fattori et al., 2005; Silva et al., 2005). Os hambúrgueres devem ser acondicionados corretamente em sacos plásticos estéreis, estocados e conservados congelados sob temperaturas $\leq 0^{\circ} \mathrm{C}$, preferencialmente $\mathrm{a}-18^{\circ} \mathrm{C}$ com tolerância de até $-12^{\circ} \mathrm{C}$ até o momento do uso. Sob refrigeração, os produtos cárneos de origem bovina devem ser armazenados a $4^{\circ} \mathrm{C}$ por até 72 horas (ICMSF, 1997; Silva Jr., 2002; Fattori et al., 2005).

Os hambúrgueres de preparo caseiro foram responsáveis por mais de $80 \%$ das infecções esporádicas por E. coli O157:H7 que ocorreram em Nova Jersey/ EUA em 1994. Ficou comprovado assim que a matéria-prima não foi o veículo de transmissão, mas sim, as mãos de cozinheiras que, após o contato com a carne moída crua, contribuíram para a contaminação cruzada com outros utensílios e alimentos (Mead et al., 1997).

As etapas ou operações consideradas de maior risco e como pontos críticos de controle na preparação de derivados cárneos cozidos são a cocção, a adição de ingredientes e o corte da matéria prima, pois são realizadas manualmente (Silva Jr., 2002).

A maioria dos casos de ETAs ocorre como conseqüência da contaminação de alimentos durante a preparação ou a embalagem por manipuladores que carreiam bactérias (nem sempre sintomáticas) nas fossas nasais, pele e mãos ou não mantêm hábitos de higiene pessoal (Bernardi et al., 2004; Siqueira Jr. et al., 2004; Adak et al., 2005).

Um estudo realizado com 7.493 pessoas nos EUA, de julho de 1996 a junho de 1997, demonstrou que $30 \%$ dos entrevistados relataram que preferiam consumir hambúrgueres mal cozidos e $93 \%$ afirmaram que, após cortarem carnes em tábuas, nem sempre lavavam a superfície desses utensílios antes de reutilizá-los, nem tampouco as mãos após o manuseio desses alimentos (Shiferaw et al., 2000).

A lavagem correta das mãos pode evitar cerca de $34 \%$ das infecções causadas por E. coli O157:H7 (Mead et al., 1997). Uma redução da contagem de mesófilos de 2,6 log e ausência de $S$. aureus e $C$. perfringens foi constatada após a lavagem das mãos de manipuladores com água e sabão líquido seguida da antissepsia com iodóforo (Almeida et al., 1995) e ainda uma considerável diminuição da contagem de Escherichia coli após a limpeza das unhas com sabão líquido e escova (Lin et al., 2003).

Utensílios como tábuas, facas, cortadores, moedores, recipientes e panos também são responsáveis pela veiculação de patógenos, tornando-se necessárias a limpeza e a desinfecção destes materiais que entram em contato com alimentos in natura, já que alimentos crus e utensílios contaminados processados simultaneamente no mesmo ambiente de trabalho podem contaminar alimentos cozidos (Macdonald et al., 2000; Andrade et al., 2003). 
O hambúrguer mal cozido tem sido apontado como um dos principais fatores de risco de infecções esporádicas e surtos causados por E. coli O157:H7 (Macdonald et al., 2000; Kassenborg et al., 2004; Sutcliffe et al., 2004; Rangel et al., 2005).

Hambúrgueres bovinos produzidos com carne pré-cozida e aquecida de maneira inadequada foram apontados como veículos de surtos de colite hemorrágica por E. coli O157:H7, nos EUA, e de Salmonella paratyphi B na França (Belongia et al., 1991; Haeghebaert et al., 2001).

Em muitos países, erros durante o processamento e o cozimento de hambúrgueres têm resultado em vários surtos, especialmente causados por Escherichia coli O157:H7. Isso demonstra que a contaminação cruzada e o tratamento térmico insuficiente são fatores diretamente relacionados com surtos causados por produtos cárneos (Macdonald et al., 2000; Haeghebaert et al., 2001; Kassenborg et al., 2004).

Omonitoramento do tempo e da temperatura indica se haverá sobrevivência ou morte dos microrganismos na cocção e no reaquecimento e quais os riscos de multiplicação durante o armazenamento e a exposição dos alimentos (Silva Jr., 2002; Jay, 2005). Cieslak et al. (1997) avaliaram as condições de cozimento de hambúrgueres em restaurantes do tipo fast food, responsáveis por um surto de $E$. coli $\mathrm{O} 157: \mathrm{H} 7$ em Las Vegas/EUA, e constataram diferenças no binômio tempotemperatura adotado pelos estabelecimentos.

Nos EUA, o FDA (2000) e o Food Safety and Inspection Service (FSIS) of United States Department of Agriculture (USDA) (FSIS, 2003) recomendam que todas as partes do hambúrguer devem ser adequadamente cozidas, principalmente suas porções mais frias (geralmente o centro geométrico), utilizando temperaturas internas de $68^{\circ} \mathrm{C}$ (FDA, 2000) ou de $71^{\circ} \mathrm{C}$ (FSIS, 2003) durante pelo menos 15 segundos. No Brasil, segue-se a Portaria ${ }^{\circ}$ 1428/MS (Brasil, 1993), que preconiza como temperatura ideal para a cocção de produtos cárneos $74^{\circ} \mathrm{C}$ por alguns segundos, embora também seja aceito o cozimento a $70^{\circ} \mathrm{C}$ por 2 minutos ou $65^{\circ} \mathrm{C}$ por 15 minutos (Silva Jr., 2002).

Reduções logaritmicas na concentração de E. coli e de Salmonella sp em hambúrgueres foram observadas após o cozimento em temperaturas adequadas (Salmon et al., 2000; Walkins \& Marks, 2002). A inativação total dessas bactérias foi constatada quando estes alimentos foram cozidos internamente a $71,1^{\circ} \mathrm{C}$ (Juneja et al., 1997; Salmon et al., 2000; Rhee et al., 2003).

Esta relação temperatura/tempo é suficiente para destruir células vegetativas, entretanto toxinas termoestáveis ou esporos não serão destruídos (Le Loir et al., 2003; Fortuna \& Franco, 2005).

O resfriamento de alimentos cozidos é outra etapa que deve ser cuidadosamente controlada a fim de se evitar que o produto permaneça sob temperaturas que possibilitem a proliferação de microrganismos que tenham sobrevivido à cocção. Microrganismos resistentes ao aquecimento e a ausência de 
refrigeração apropriada após a cocção permitem a germinação e a multiplicação em produtos cárneos cozidos (Haeghebaer et al., 2001; Fortuna \& Franco, 2005).

Carnes cozidas devem ser refrigeradas após atingirem $55^{\circ} \mathrm{C}$ em sua superfície e a temperatura no centro geométrico deve cair a $21^{\circ} \mathrm{C}$, dentro de duas horas, e a $4^{\circ} \mathrm{C}$ dentro de mais seis horas (Silva Jr., 2002; Brasil, 2003).

O reaquecimento bem executado é tão importante quanto a cocção inicial, pois as células bacterianas sobreviventes proliferam-se, devendo ser destruídas durante o novo aquecimento (Fortuna \& Franco, 2005). Recomenda-se que nesta etapa todas as porções dos hambúrgueres cozidos devam atingir novamente a temperatura de segurança, conforme o que foi descrito para a cocção, ou seja, de $74^{\circ} \mathrm{C}$ durante 15 segundos (FDA, 2000; Silva Jr., 2002).

\section{INCIDÊNCIA E IMPACTO SOCIOECONÔMICO DOS SURTOS DE ENFERMIDADES TRANSMITIDAS POR ALIMENTOS}

Um caso de doença alimentar corresponde ao incidente no qual uma pessoa torna-se doente após a ingestão de um alimento considerado contaminado com base em evidência epidemiológica ou análise laboratorial (Haeghebaer et al., 2001; Sutcliffe et al., 2004). Um surto pode ser definido como um episódio caracterizado pela ocorrência de dois ou mais casos de uma mesma enfermidade, resultante da ingestão de um alimento comum (Olsen et al., 2000; Bender et al., 2004; Rangel et al., 2005).

Os dados reais da incidência das ETAs permanecem desconhecidos, apenas $1 \%$ a $10 \%$ desses episódios são relatados anualmente (FAO/WHO, 2002). A maioria não é analisada sistematicamente por organismos internacionais, nacionais ou regionais em razão de falhas na coleta dos dados disponíveis. A ocorrência dos casos é muitas vezes subestimada por ausência de atendimento médico, diagnóstico impreciso ou falta de notificação às autoridades sanitárias (Lindqvist et al., 2001; Bender et al., 2004; Adak et al., 2005).

Anualmente, nos EUA, ocorrem cerca de 76 milhões de casos de ETAs, 323.000 hospitalizações e 5.000 mortes. Cerca de 62 milhões das ETAs são de etiologia não identificada (Mead et al., 1999). A incidência total de gastrenterites agudas varia entre 250 e 350 milhões por ano, das quais $25 \%$ a $30 \%$ são diretamente associadas a ETAs (McCabe-Sellers \& Beattie, 2004), enquanto as complicações crônicas que ocorrem em 2\% a 3\% dos casos raramente são notificadas (Lindqvist et al., 2001). Os custos anuais com doentes, funerais, ações legais e pagamento dos prejuízos associados a ETAs nesse país giram em torno de 6,5 bilhões de dólares (USGAO, 2001).

Olsen et al. (2000) relataram a ocorrência nos EUA, entre 1993 e 1997, de 2.751 surtos e 86.058 casos de ETAs. As bactérias foram responsáveis pela maioria dos surtos (75\%) e dos casos (86\%), enquanto $6 \%$ dos surtos e $8 \%$ dos casos foram causados por vírus, $2 \%$ e $5 \%$ por parasitas e $17 \%$ e $1 \%$ por agentes 
químicos, respectivamente. As principais bactérias foram Salmonella, E. coli, C. perfringens, $S$. aureus, Shigella, Campylobacter, C. botulinum e B. cereus, e a carne bovina um dos principais veículos. Ainda nesse país, no período de 2000 a 2005, foram relatados 6.376 surtos e 127.065 casos de ETAs. Cerca de $48 \%$ dos surtos e $47 \%$ dos casos foram de etiologia bacteriana, $41 \%$ e $50 \%$ foram causados por vírus, $1 \%$ e $1 \%$ por parasitas e $10 \%$ e $2 \%$ por agentes químicos, respectivamente. Entre 2003 e 2004, os produtos cárneos bovinos foram responsáveis por cerca de 3\% dos surtos (CDC, 2004a).

Os surtos notificados de ETAs de etiologia conhecida, nos EUA, ocorreram com maior freqüência em estabelecimentos comerciais e institucionais (78\%) e em menores proporções em residências privadas (22\%) (Olsen et al., 2000). Entretanto, os casos esporádicos por E. coli $\mathrm{O} 157: \mathrm{H} 7$ são mais freqüentemente relacionados com o consumo de hambúrgueres de preparação caseira (Rivas et al., 2001). Normalmente, os surtos provocados por alimentos caseiros, relacionados com inadequadas práticas de preparação, são menos relatados em virtude de ser menor tanto o número de pessoas acometidas quanto a gravidade dos casos (Olsen et al., 2000; FAO/WHO, 2002).

A E. coli $\mathrm{O} 157: \mathrm{H} 7$ foi identificada pela primeira vez em surtos de colite hemorrágica nos estados de Oregon e Michigan/EUA, associada ao consumo de hambúrguer mal cozido em restaurantes de uma cadeia de fast food (Riley et al., 1983). De 1982 a 2002, foram reportados 350 surtos, 8.598 casos esporádicos, 1.493 hospitalizações, 354 casos de colite hemorrágica e 40 óbitos por $E$. coli $\mathrm{O} 157$ em 49 estados dos EUA, sendo os produtos cárneos moídos de origem bovina os veículos identificados em 75 surtos e os hambúrgueres bovinos em 27 surtos. Nesse período, entre os surtos associados a hambúrgueres contaminados, cinco ocorreram em restaurantes do tipo fast food, sendo dois em 1982, um em 1992 a 1993, um em 1995, e um em 1999 (Rangel et al., 2005). Seis surtos similares envolvendo hambúrgueres contaminados por esta bactéria, nos EUA, também foram notificados em 2003 (três) e 2004 (três) (CDC, 2004a).

Cerca de 73.000 casos infecciosos, 2.000 hospitalizações e 60 óbitos causados por essa bactéria são notificados a cada ano nesse país, cujos gastos anuais são estimados em 405 milhões de dólares e os custos de caso/indivíduo variam de 26 dólares a 6,2 milhões de dólares (Frenzen et al., 2005).

A incidência anual de infecções esporádicas de E. coli O157:H7 nos EUA, de 1996 a 1999, foi estimada em 1,9 a 2,3 casos/100.000 habitantes (Bender et al., 2004 ) e não apresentou diferenças significativas até 2002 , sendo apenas $8 \%$ mais baixa em relação a 1996 (Vugia et al., 2003). Entretanto, houve um declínio de $43,3 \%$ no percentual de positividade desta bactéria em amostras de carne moída em 2004 em relação ao ano de 2003, e mais de 80\% em relação ao ano 2000 (USDA, 2005), graças à implementação de medidas que asseguraram a eliminação ou redução dessa bactéria nestes produtos pelo FSIS (FSIS, 2003) e pelo FDA (FDA, 2000) (Rangel et al., 2005; USDA, 2005). 
Salmonella, S. aureus, C. perfringens, C. botulinum, B. cereus e E. coli O157:H7 foram os principais agentes responsáveis por surtos de ETAs no Japão, Coréia (Lee et al., 2001), Suécia (Lindqvist et al., 2001), Canadá (Macdonald et al., 2000; Lee \& Middleton, 2003), Austrália (Dalton et al., 2004), Inglaterra e País de Gales (Adak et al., 2005) no período de 1981 a 2001. A carne bovina e seus produtos derivados foram veículos importantes desses surtos, sendo identificadas em 17\% a 30\% dos episódios (Lindqvist et al., 2001; Dalton et al., 2004; Adak et al., 2005).

A notificação de ETAs tem sido evidenciada em diferentes países. $\mathrm{Na}$ Coréia e no Japão, de 1981 a 1995, foi estimada uma prevalência média de casos de 2,44/100.000 indivíduos e de 28,01/100.000 indivíduos e a taxa de mortalidade de $0,74 \%$ e 0,3\%, respectivamente (Lee et al., 2001); na Suécia, de 1998 a 1999, foram reportados 85 surtos e 183 casos, representando um custo anual de 123 milhões de dólares para a economia desse país (Lindqvist et al., 2001); no Canadá, de 1992 a 2001, 101.141 casos com incidência média anual de 22,3 casos de Salmonella/100.000 indivíduos e de 3,7 casos de E. coli O157/100.000 indivíduos (Lee \& Middleton, 2003); na Austrália, de 1995 a 2000, 214 surtos e 20 óbitos (Dalton et al., 2004); na Inglaterra e País de Gales, de 1996 a 2000, 1.724 .315 casos, 21.997 hospitalizações e 687 óbitos/ano (Adak et al., 2005).

No Brasil, têm sido realizados estudos visando evidenciar a presença de $E$. coli $\mathrm{O} 157: \mathrm{H7}$ em hambúrgueres, frigoríficos e indústrias nas regiões Sul e Sudeste. A bactéria não foi detectada em nenhuma das amostras analisadas, atestando, senão a ausência, pelo menos uma baixa freqüência desse patógeno em produtos cárneos brasileiros (Silveira et al., 1999; Silva et al., 2001).

As infecções por Salmonella causam aproximadamente 1,4 milhões de casos de ETAs, 16.000 hospitalizações e 600 óbitos por ano nos EUA, sendo responsáveis por grandes perdas econômicas estimadas na ordem de 2,9 bilhões de dólares por ano (USDA, 2003), com custo médio de 1.322 dólares/caso (Lindqvist et al., 2001). S. enteritidis foi o agente etiológico mais identificado, considerado responsável por $55 \%$ dos surtos ocorridos entre 1993 e 1997 nos EUA (Olsen et al., 2000), enquanto em 2002 , de $49 \%$ dos casos de ETAs por Salmonella ocorridos no país, $19 \%$ foi causado por $S$. typhimurium, $15 \%$ por $S$. enteritidis e $14 \%$ S. newport (Vugia et al., 2003). Em 2002, em cinco estados americanos, ocorreu um surto infeccioso por $S$. newport multiresistente a antibióticos com 45 casos confirmados e um óbito associado ao consumo de carne moída bovina crua ou mal cozida (Zansky et al., 2002). Em 2003 e 2004 , surtos por S. typhimurium, S. enteritidis, S. newport e S. oranienburg veiculados por produtos bovinos moídos foram reportados no país (CDC, 2004a).

Surtos de salmonelose envolvendo a carne moída e hambúrguer bovino cru ou mal cozido têm sido também notificados na França (Haeghebaert et al., 2001), no Canadá (Lee \& Middleton, 2003), na Austrália (Dalton et al., 2004), na Argentina (Di Pietro et al., 2004), na Inglaterra e País de Gales (Adak et al., 2005).

No Brasil, nos estados do Rio Grande do Sul e São Paulo, a salmonelose tem sido a ETA de maior ocorrência desde 1993 (Nadvorny et al., 2004). De 1996 a 
2000, ocorreram, em São Paulo, 4.581 casos de ETAs por Salmonella sp, sendo a $S$. enteritidis a mais prevalente $(32,7 \%)$ e a carne bovina responsável por $11 \%$ desses episódios (Tavechio et al., 2002). Em 2000, dos 99 surtos de ETAs ocorridos no Rio Grande do Sul, 74 (74,7\%) foram ocasionados por Salmonella sp, estando a carne bovina envolvida em $2,5 \%$ dos surtos (Nadvorny et al., 2004).

Os casos esporádicos causados por $B$. cereus, $C$. perfringens, $C$. botulinum e $S$. aureus normalmente não são relatados, se o fossem este número seria dez vezes maior do que o número de surtos identificados (Mead et al., 1999).

Nos EUA, são estimados, aproximadamente, 250 mil casos de toxinoses alimentares por $C$. perfringens e sete óbitos por ano (Wen \& McClane, 2004). Entre 1993 e 2004, foram identificados no país alguns surtos causados por esta bactéria, associados ao consumo de carne moída cozida (Olsen et al., 2000; CDC, 2004a). Na Inglaterra e País de Gales, de 1996 a 2000, foram relatados 168.436 casos de toxinoses por C. perfringens, o que ocasionou 709 hospitalizações e 177 óbitos, sendo as carnes de origem bovina e aviária os alimentos mais envolvidos (Adak et al., 2005). Surtos similares causados por este patógeno, tendo a carne e o hambúrguer de origem bovina como veículos, também foram identificados na Austrália, entre 1995 e 2000, e no Brasil, entre 1998 e 2001 (Câmara, 2002; Dalton et al., 2004).

Entre 1990 e 2000, foram constados 263 casos de botulismo nos EUA, com uma incidência anual de $0,1 / 1.000 .000$ e média anual de 23 casos. Os produtos enlatados caseiros foram responsáveis pela maioria dos casos, assim com a toxina botulínica tipo A, que foi identificada em mais de $50 \%$ dos episódios, ao passo que somente um surto e um caso associado a hambúrguer bovino contaminado por $C$. botulinum foi confirmado neste período (Sobel et al., 2004). Na Polônia, foram descritos 78 casos e dois óbitos por botulismo em 2003, sendo os pratos cárneos envolvidos em 24,4\% dos episódios (Czerwinski et al., 2005). No Brasil, no estado de Goiás, de acordo com levantamentos realizados pelo Centro de Informações Toxicológicas de Goiás (CIT), da Superintendência de Vigilância Sanitária Estadual, ocorreu um caso de botulismo provocado pelo consumo de sanduíche de carne contaminada (Brasil, 2001b).

Aproximadamente 185.060 casos de toxinoses alimentares, 1.753 hospitalizações e dois óbitos por S. aureus são estimados por ano nos EUA (Mead et al., 1999) e 9.196 casos e 232 hospitalizações na Inglaterra e País de Gales (Adak et al., 2005). No período de 1993 a 2004, surtos de toxinoses causados por este patógeno, tendo a carne e o hambúrguer bovinos confirmados como veículos, foram evidenciados no Brasil (Câmara, 2002), nos EUA (Olsen et al., 2000; CDC, 2004a) e na Europa (Lindqvist et al., 2001; Adak et al., 2005).

Mesmo sendo notificados anualmente 27.360 casos de ETAs por B. cereus nos EUA (Mead et al., 1999), a notificação dessa bactéria em surtos associados ao consumo de carnes contaminadas é baixa ou nula em diferentes países (Lindqvist et al., 2001; Câmara, 2002; CDC, 2004a). 
Durante o período de 1996 a 2003, estimou-se que a incidência de várias infecções causadas por patógenos emergentes decresceu significantemente nos EUA: por E. coli $\mathrm{O} 157 \mathrm{em} 42 \%$ e por Salmonella em 17\% (CDC, 2004c). Em 2004, o decréscimo foi de até $80 \%$ para E. coli O157 (USDA, 2005). A adoção de medidas de controle por órgãos governamentais e pelas indústrias de alimentos que têm investido em segurança alimentar durante a fabricação de produtos cárneos e também em educação alimentar para seus consumidores resultaram em uma redução de Salmonella em carnes durante este período e de E. coli $\mathrm{O} 157$ em hambúrgueres a partir de 2002 e, conseqüentemente, em maior prevenção das ETAs (CDC, 2004c; Rangel et al., 2005; USDA, 2005).

Esses dados comprovam que grande parte das ETAs que ocorrem mundialmente poderia ser evitada se mais pesquisas fossem realizadas em benefício da segurança alimentar (CDC, 2004c; Rangel et al., 2005; USDA, 2005).

\section{ABSTRACT}

Ready-to-eat ground beef hamburger: legal aspects and bacterial risks

The present review describes the necessary basic aspects to assure the hygienicsanitary quality of bovine meat, more specifically regarding the ready-to-eat ground beef hamburger, which is currently one of the foods more produced in large scale and increasingly consumed in Brazil. The microbiological limits and patterns which must be adopted to guarantee a correct interpretation among the results of microbiological analysis, the factors that contribute to the occurrence of foodborne disease outbreaks and the need to implement good practice production systems which aim to identify the microbiological hazards and risks were important parameters approached throughout this work. Furthermore, the legal aspects and the bacterial hazards that compromise the quality of these provisions exposed for selling or consumption are described, with the intention of, above all, preventing or minimizing the number of foodborne diseases, having seen that these represent one of the most disseminated problems within public health worldwide.

KEYWORDS: Hamburgers. Microorganisms. Food transmitted diseases.

\section{REFERÊNCIAS}

1. Adak GK, Meakins SM, Yip H, Lopman BA, O’Brien SJ. Disease risks from foods, England and Wales, 1996-2000. Emerg Infect Dis 11: 365-372, 2005.

2. Almeida RCC, Kuaye AY, Serrano AM, Almeida PF. Avaliação e controle da qualidade microbiológica de mãos de manipuladores de alimentos. Rev Saúde Pública 29: 290-294, 1995.

3. Andrade NJ, Silva RMM, Brabes KCS. Avaliação das condições microbiológicas em unidades de alimentação e nutrição. Ciênc Agrotec 27: 590-596, 2003.

4. Anuário da Pecuária Brasileira (ANUALPEC). FNP. - Consultoria e Comércio. São Paulo: Argos, 2003. p. 442. 
5. Belongia EA, Macdonald KL, Parham GL, White KE, Korlath JA, Lobato MN, Strand SM, Casale KA, Osterholm MT. An outbreak of Escherichia coli O157:H7 colitis associated with consumption of precooked meat patties. J Infect Dis 164: 338-343, 1991.

6. Bender JB, Smith KE, McNeves AA, Rabatsky-Ehr TR, Segler SD, Hawkins MA, Spina NL, Keene WE, Kennedy MH, Van Gilder TJ, Hedberg CW. Factors affeting surveillance data on Escherichia coli O157 infections colleted from FoodNet sites, 1996- 1999. Clin Infect Dis 38: S157-S164, 2004.

7. Bergmann GP, Ritter R, Santos D. Contaminação bacteriana da carne moída bovina comercializada em bancas do mercado público de Porto Alegre, RS. Rev Hig Alimentar 15: 50-56, 2001.

8. Bernardi E, De Armas RD, Caldeira MF, Ribeiro GA. Caracterização microbiológica e sorológica de linhagens de Escherichia coli, isoladas de carne moída comercializada em Pelotas, RS. Rev Hig Alimentar 18: 82-86, 2005.

9. Bessa MC, Costa M, Cardoso M. Prevalência de Salmonella sp em suínos abatidos em frigoríficos do Rio Grande do Sul. Pesq Vet Bras 24: 80-84, 2004.

10. Brasil. Ministério da Agricultura. Decreto $n^{\circ} 30.691$ de 29 de março de 1952. RIISPOA Regulamento da Inspeção Industrial e Sanitária de Produtos de Origem Animal. Brasília: Ministério da Agricultura, 1952.

11. Brasil. Ministério da Agricultura e do Abastecimento. Portaria no 368 de 04 de setembro de 1997. Regulamento técnico sobre as condições higiênicos sanitárias e de boas práticas de elaboração para estabelecimentos elaboradores/ industrializadores de alimentos. Brasília: Ministério da Agricultura e do Abastecimento, 1997a.

12. Brasil. Ministério da Agricultura e do Abastecimento. Portaria $\mathrm{n}^{\circ} 371$ de 04 de setembro de 1997. Regulamento técnico para rotulagem de alimentos. Brasília: Ministério da Agricultura e do Abastecimento, 1997b.

13. Brasil. Ministério da Agricultura e do Abastecimento. Secretaria de Defesa Agropecuária/ Órgão: DIPOA - Departamento de Inspeção de Produtos de Origem Animal. Regulamento técnico de identidade e qualidade de hambúrguer, anexo IV. Diário Oficial da União, Brasília, 3 de agosto de 2000.

14. Brasil. Ministério da Saúde. Portaria $n^{\circ} 1428$ de 26 de novembro de 1993. Regulamento técnico para inspeção sanitária de alimentos. Diário Oficial da União. Brasília, 31 maio 1993.

15. Brasil. Ministério da Saúde. Portaria ${ }^{\circ} 2535$ de 24 de outubro de 2003. Regulamento técnico para o controle higiênico-sanitário em empresas de alimentos. Diário Oficial da União. Brasília, 24 out. 2003.

16. Brasil. Ministério da Saúde. Resolução RDC n 12 de 02 de janeiro de 2001 da Agência Nacional de Vigilância Sanitária-ANVISA. Regulamento técnico sobre padrões microbiológicos para alimentos. Diário Oficial da União. Brasília, 10 jan. 2001a.

17. Buzby JC. Older adults at risk of complications from microbial foodborne illness. Food Review 25: 30-35, 2002.

18. Callaway TR, Elder RO, Keen JE, Anderson RC, Nisbet DJ. Forage feeding to reduce preharvest Escherichia coli populations in cattle, a review. J Dairy Sci 86: 852-860, 2003.

19. Câmara SAV. Surtos de toxinfecções alimentares no Estado de Mato Grosso do Sul, 1998-2001. Campo Grande [Monografia de Especialização em Saúde Pública - Escola de Saúde Pública Dr. Jorge David Nasser/MS], 2002.

20. Centers for Disease Control and Prevention (CDC). Foodborne outbreak response and surveillance unit. U.S. Foodborne disease outbreaks. June, 2004a. Disponível em: http://www.cdc.gov/ foodborneoutbreaks/us_outb.htm. Acesso em: 22 fev. 2006.

21. Centers for Disease Control and Prevention (CDC). National Center for Infectious Diseases. Division of Bacterial and Mycotic Diseases. Yersinia enterocolitica. February, 2004b. Disponível em: http://www.cdc.gov/ncidod/dbmd/diseaseinfo/yersinia_g.htm. Acesso em: 19 out. 2005.

22. Center for Disease Control and Prevention (CDC). Preliminary foodnet data on the incidence of infection with pathogens transmitted commonly through food - selected sites, United States, 2003. MMWR 53: 338-343, 2004c. 
23. Chesca AC, Caetano AM, Leite APC, Polveiro AM, Terra AD, Lyra FS, Zaidan MCC, Okura MH. Avaliação das temperaturas de pistas frias e pistas quentes em restaurantes da cidade de Uberaba, MG. Rev Hig Alimentar 15: 38-43, 2001.

24. Cieslak PR, Noble SJ, Maxson DJ, Empey LC, Ravenholt O, Legarza G, Tuttle J, Doyle MP, Barrett TJ, Wells JG, McNamara AM, Griffin PM. Hamburger-associated Escherichia coli O157:H7 infection in Las Vegas: a hidden epidemic. Am J Public Health 87: 176-180, 1997.

25. Cogco LG, Vázquez EM, Pérez PA, Andarde MCG. Serotipos de Salmonella identificados en los servicios de salud de México. Salud Publica México 42: 1-9, 2000.

26. Czerwinski M, Czarkowski MP, Kondej B. Botulism in Poland in 2003. Przegl Epidemiol 59: 281-287, 2005.

27. Dalton CB, Gregory J, Kirk MD, Stafford RJ, Givney R, Kraa E, Gould D. Foodborne disease outbreaks in Australia, 1995 to 2000. Commun Dis Intell 28: 211-224, 2004.

28. Di Pietro S, Haritchabalet K, Cantoni G, Iglesias L, Mancini S, Temperoni A, Labanchi JL, Barbarossa N, Garcia MT, Cofre M, Rosales S, Herrero E, Bigatti R, Orellana O, Larrieu E. Surveillance of foodborne diseases in the province of Rio Negro, Argentina, 1993-2001. Medicina (B Aires) 64: 120-124, 2004.

29. Elder RO, Keen JE, Siragusa GR, Barkocy-Gallagher GA, Koohmaraie M, Laegreid WW. Correlation of entero-hemorrhagic Escherichia coli O157:H7 prevalence in feces hides and carcasses of beef cattle during processing. Proc Natl Acad Sci 97: 2999-3003, 2000.

30. Fattori FFA, Souza LC, Braoios A, Ramos APD, Tashima NT, Neves TRM, Barbosa RL. Aspectos sanitários em "trailers" de lanche no município de Presidente Prudente, SP. Rev Hig Alimentar 19: 54-62, 2005.

31. Feitosa, T. Contaminação, Conservação e Alteração da Carne. Fortaleza: Embrapa - CNPAT. Documentos, 34, 1999.

32. Food and Agriculture Organization of United Nations (FAO) / World Health Organization (WHO). Statistical information on food-borne disease in Europe microbiological and chemical hazards. In: FAO/WHO Pan-European conference on food safety and quality; Budapest, Hungary, 25-28 february 2002. PEC 01/04, rev.1. p. 1-15.

33. Food and Drug Administration (FDA). Center for Food Safety and Applied Nutrition (CFSAN). Bad Bug Book. Escherichia coli O157:H7. December 2005a. Disponível em: http://www.cfsan.fda. gov/ mow/chap15.html. Acesso em: 18 jan. 2006.

34. Food and Drug Administration (FDA). Center for Food Safety and Applied Nutrition (CFSAN). Bad Bug Book. Salmonella spp. December 2005b. Disponível em: http://www.cfsan.fda.gov/ mow/ chap1.html. Acesso em: 18 jan. 2006.

35. Food and Drug Administration (FDA). Center for Food Safety and Applied Nutrition (CFSAN). Bad Bug Book. Staphylococcus aureus. December 2005c. Disponível em: http://www.cfsan.fda. gov/ mow/chap3.html. Acesso em: 18 jan. 2006.

36. Food and Drug Administration (FDA). Food Code, 1999. In: Food, Chapter 3. Washington, DC: U.S. Department of Health and Human Services do Center for Food Safety and Applied Nutrition (CFSAN). March 2000. Disponível em: http://vm.cfsan.fda.gov/ dms/fc99-3.html. Acesso em: 14 fev. 2006.

37. Food Safety and Inspection Service (FSIS). United States Department of Agriculture (USDA). Washington, D.C. 20250-3700. Color of cooked ground beef as it relates to doneness. April 2003. Disponível em: http://www.fsis.usda.gov/OA/pubs/colortech.htm. Acesso em: 14 fev. 2006.

38. Forsythe SJ. A flora microbiana dos alimentos. Microbiologia da Segurança Alimentar. 1. ed., Porto Alegre: Artmed, 2002.

39. Fortuna JL, Franco RM. Uma revisão sobre o Clostridium perfringers como agente etiológico de doenças transmitidas por alimentos (D.T.A.). Rev Hig Alimentar 19: 48-54, 2005.

40. Frenzen PD, Drake A, Ângulo FJ. Economic cost of illness due Escherichia coli O157 infections in the United States. J Food Prot 68: 2623-2630, 2005.

41. Garcia RF, Bliska FMM. Caracterização do consumo de carnes no Brasil. Rev Nac Carne 284: 108-109, 2000. 
42. Germano MIS, Germano PML, Castro AP, Andrigheto C, Babadopulos P, Koshio S, Pedro SCM, Colombari V. Comidas de ruas: prós e contras. Rev Hig Alimentar 14: 27-33, 2000.

43. Gill CO, Bryant J, Badoni M. Effects of hot water pasteurizing treatments on the microbiological condition of manufacturing beef used for hamburger patty manufacture. Int J Food Microbiol 63: 243-256, 2001.

44. Goiás. Secretaria de Estado da Saúde de Goiás. Superintendência de Vigilância Sanitária. Centro de Informação Toxicológicas de Goiás (CIT). Casos registrados de intoxicação humana por agente tóxico em Goiás em 1999 e em 2000. Goiânia, 2001b.

45. Haeghebaert S, Duché L, Gilles C, Masini B, Dubreuil M, Minet JC, Bouvet P, Grimont F, Delarocque Astagneau E, Vaillant V. Minced beef and human salmonellosis: review of the investigation of three outbreaks in France. Euro surveillance 6: 21-26, 2001.

46. International Commission on Microbiological Specifications for Foods (ICMSF). Serviços de alimentos. In: APPCC na Qualidade e Segurança Microbiológica de Alimentos. São Paulo: Livraria Varela, 1997. p.295-314.

47. Jarraud S, Peyrat MA, Lim A, Tristan A, Bès M, Mougel C, Etienne J, Vandenesch F, Bonneville M, Lina G. egc, a highly prevalent operon of enterotoxin gene, forms a putative nursery of superantigens in Staphylococcus aureus. J Immunol 166: 669-677, 2001.

48. Jay JM. Microbiologia de Alimentos. 6. ed., Porto Alegre: Artmed, 2005.

49. Jo MY, Kim JH, Lim JH, Kang MY, Koh HB, Park YH, Yoon DY, Chae JS, Eo SK, Lee JH. Prevalence and characteristics of Escherichia coli O157:H7 from major food animals in Korea. Int J Food Microbiol 95: 41-49, 2004.

50. Juneja VK, Snyder Jr OP, Williams AC, Marmer BS. Thermal destruction of Escherichia coli O157:H7 in hamburger. J Food Prot 60: 1163-1166, 1997.

51. Kasowski EJ, Gackstetter GD, Sharp TW. Foodborne illness: new developments concerning and old problem. Curr Gastroenterol Rep 4: 308-318, 2002.

52. Kassenborg HD, Hedberg CW, Hoekstra M, Evans MC, Chin AE, Marcus R, Vugia DJ, Smith K, Ahuja SD, Slutsker L, Griffin PM. Farms visits and undercooked hamburgers as major risk factors for sporadic Escherichia coli O157:H7 infection: data from a case-control study in 5 FoodNet sites. Clin Infect Dis 38:S271-278, 2004.

53. Koneman EW, Allen SD, Janda WM, Schreckenberger PC, Winn Jr WC. Diagnóstico Microbiológico - Texto e Atlas Colorido. 5. ed., Rio de Janeiro: Editora Médica e Científica, 2001.

54. Le Loir Y, Baron F, Gautier M. Staphylococcus aureus and food poisoning. Genet Mol Res 2: 63-76, 2003.

55. Lee MB, Middleton D. Enteric illness in Ontario, Canada, from 1997 to 2001. J Food Prot 66: 953-961, 2003.

56. Lee WC, Lee MJ, Kim JS, Park SY. Foodborne illness outbreaks in Korea and Japan studied retrospectively. J Food Prot 64: 899-902, 2001.

57. Levrè E, Valentini $\mathrm{P}$, Chiaverini F. Presenza di E. coli $\mathrm{O} 157$ verocitotossigeni in hamburger di carne bovina. Ann Ig 12: 131-137, 2000.

58. Lima JX, Oliveira LF. O crescimento do restaurante self-service: aspectos positivos e negativos para o consumidor. Rev Hig Alimentar 19: 45-53, 2005.

59. Lin CM, Wu FM, Kim HK, Doyle MP, Michael BS, Williams LK. A comparison of hand washing techniques to remove Escherichia coli and calicivirus under natural or artificial fingernails. $J$ Food Prot 66: 2296-2301, 2003.

60. Lindqvist R, Andersson Y, Lindbäck J, Wegscheider M, Eriksson Y, Tideström L, Lagerqvist-Widh A, Hedlund KO, Löfdahl S, Svensson L, Norinder A. A one-year study of foodborne illnesses in the municipality of Uppsala, Sweden. Emerg Infect Dis 7: 588-592, 2001.

61. Macdonald C, Drew J, Carlson R, Dzogan S, Tataryn S, Macdonald A, Ali A, Amhed R, Easy R, Clark C, Rodgers F. Outbreak of Escherichia coli O157:H7 leading to the retall of retail ground beef - Winnipeg, Manitoba, May1999. CCDR 26-13, 2000. 
62. Martins SCS, Albuquerque LMB, Serio J, Mattei ACML, Rodrigues MSV. Avaliação microbiológica de pontos críticos de controle no fluxograma de preparação de carne bovina em unidade de nutrição. Rev Hig Alimentar 15:84-89, 2001.

63. McCabe-Sellers BJ, Beattie SE. Food safety: emerging trends in foodborne illness surveillance and prevention. J A Diet Assoc 104: 1708-1717, 2004.

64. Mead PS, Finelli L, Lambert-Fair MA, Champ D, Townes J, Hutwagner L, Barret T, Spitalny K, Mintz E. Risk factors for sporadic infection with Escherichia coli O157:H7. Arch Intern Med 157: 204-208, 1997.

65. Mead PS, Slutsker L, Dietz V, McCaig LF, Bresee JS, Shapiro C, Griffin PM, Tauxe RV. Foodrelated illness and death in the United States. Emerg Infect Dis 5: 607-625, 1999.

66. Munuera I, Garcia D, Ibáñez JJ. Niveles guia, limites maximos admisibles, criterios microbiologicos y otros valores de referencia en analisis microbiologicos de alimentos y bebidas. Vacios legales, emision de dictamenes. Alimentaria :39-42, 1997.

67. Nadvorny A, Figueiredo DMS, Schmidt V. Ocorrência de Salmonella sp. Em surtos de doenças transmitidas por alimentos no Rio Grande do Sul em 2000. Acta Scientiae Veterinariae 32: 47-51, 2004.

68. Nataro JP, Kaper, JB. Diarrheagenic Escherichia coli. Clin Microbiol Rev 11: 142-201, 1998.

69. Olsen SJ, MacKinon LC, Goulding JS, Bean NH, Slutsker L. Surveillance for foodborne disease outbreaks, United States, 1993-1997. MMWR 49: 1-51, 2000.

70. Omisakin F, MacRae M, Ogden ID, Strachan NJC. Concentration and prevalence of Escherichia coli $\mathrm{O} 157$ in cattle feces at slaughter. Appl Environ Microbiol 69: 2444-2447, 2003.

71. Organização Mundial da Saúde (OMS). Segurança básica para profissionais de saúde. 1. ed. São Paulo: Manole, 2002.

72. Patil SR, Cates S, Morales R. Consumer food safety knowledge, practices, and demographic differences: findings from a meta-analysis. J Food Prot 68: 1884-1894, 2005.

73. Picchi V. Higienização em estabelecimentos de abate de bovinos. Revista Nacional da Carne, v. 332, Outubro de 2004. Disponível em: http://www.dipemar.com.br/carne/332/materia_especial_carne. htm. Acesso em: 8 fev. 2006.

74. Prado IN, Matsushita M, Visentainer JV, Souza NE. Carne bovina brasileira: realidade e perspectivas. Revista Nacional da Carne, v. 326, Abril de 2004. Disponível em: http://www.dipemar. com.br/carne/326/index.htm. Acesso em: 6 out. 2005.

75. Rangel JM, Sparling PH, Crowe C, Griffin PM, Swerdlow DL. Epidemiology of Escherichia coli O157:H7 outbreaks, United States, 1982-2002. Emerg Infect Dis 11: 603-609, 2005.

76. Rhee MS, Lee SY, Hillers VN, McCurdy SM, Kang DH. Evaluation of consumer-style cooking methods for reduction of Escherichia coli O157:H7 in ground beef. J Food Prot 66: 1030-1034, 2003.

77. Riley LW, Remis RS, Helgerson SD, McGee HB, Wells JG, Davis BR, Heberts RJ, Olcott HM, Johnson LM, Hargrett NT, Blake PA, Cohen ML. Hemorrhagic colitis associated with a rare Escherichia coli serotype. N Engl J Med 308: 681-685, 1983.

78. Rivas M, Caletti MG, Chinen I, Refi SM, Roldán CD, Chillemi G, Fiorilli G, Bertolotti A, Aguerre L, Estanis SS. Home-prepared hamburger and sporadic hemolytic syndrome, Argentina. Emerg Infect Dis 9: 1184-1186, 2003.

79. Sabota JM, Hoppes WL, Ziegler Jr JR, Dupont H, Mathewson J, Rutecki GW. A new variant of food poisoning: enteroinvasive Klebsiella pneumoniae and Escherichia coli sepsis from a contaminated hamburger. Am J Gastroenterol 93: 118-119, 1998.

80. Salmon CP, Knize MG, Panteleakos FN, Wu RW, Nelson DO, Felton JS. Minimization of heterocyclic amines and thermal inactivation of Escherichia coli in fried ground beef. J Natl Cancer Inst 92: 1773-1778, 2000.

81. Schlundt J. New directions in foodborne disease prevention. Int J Food Microbiol 78: 3-17, 2002.

82. Schoeni JL, Wong AC. Bacillus cereus food poisoning and its toxins. J Food Prot 68: 636-648, 2005.

83. Shiferaw B, Yang S, Cieslak P, Vugia D, Marcus R, Koehler J, Deneen V, Angulo F. Prevalence of high-risk food consumption and food-handling practices among adults: a multistate survey, 1996 to 1997. The Foodnet Working Group. J Food Prot 63: 1538-1543, 2000. 
84. Silva CA, Sousa EL, Sousa CP. Estudo da qualidade sanitária da carne moída comercializada na cidade de João Pessoa, PB. Rev Hig Alimentar 18: 90-93, 2004.

85. Silva Jr. EA. Manual de Controle Higiênico-Sanitário em Alimentos. 5. ed. São Paulo: Livraria Varela, 2002.

86. Silva CRB, Barros JJC, Miranda FA, Rossi DA. Efeito do congelamento e resfriamento na preservação de Escherichia coli (ATCC25922) e Staphylococcus aureus (ATCC9801), inoculadas em carne moída bovina estocada para investigação de surtos de toxinfecção alimentar. Rev Hig Alimentar 19: 95-98, 2005.

87. Silva N, Silveira NFA, Contreras C, Beraquet NJ. Ocorrência de Escherichia coli O157:H7 em produtos cárneos e sensibilidade dos métodos de detecção. Ciênc Tecnol Aliment 21: 223-227, 2001.

88. Silveira NFA, Silva N, Contreras C, Miyagusku L, Baccin MDF, Koono E, Beraquet NJ. Occurence of Escherichia coli:H7 in hamburgers produced in Brazil. J Food Prot 62: 1333-1335, 1999.

89. Siqueira Jr. WM, Careli RT, Andrade NJ, Mendonça RCS. Qualidade microbiológica de equipamentos, utensilios e manipuladores de uma indústria de processamento de carnes. Revista Nacional da Carne, v. 326, Abril de 2004. Disponível em: http://www.dipemar.com.br/carne/326/ materia_especial2_carne.htm. Acesso em: 8 fev. 2006.

90. Sobel J, Mixter CG, Kolhe P, Gupta A, Guarner J, Zaki S, Hoffman NA, Songer JG, FremontSmith M, Fischer M, Killgore G, Britz PH, MacDonald C. Necrotizing enterocolitis associated with Clostridium perfringens type A in previously healthy north american adults. J Am Coll Surg 201: 48-56, 2005.

91. Sobel J, Tucker N, Sulka A, McLaughlin J, Maslanka S. Foodborne botulism in the United States, 1990-2000. Emerg Infect Dis 10: 1606-1611, 2004.

92. Soriano JM, Font G, Rico H, Molto JC, Manes J. Incidence of enterotoxigenic staphylococci and their toxins in foods. J Food Prot 65: 857-860, 2002.

93. Stampi S, Caprioli A, De Luca G, Quaglio P, Sacchetti R, Zanetti F. Detection of Escherichia coli O157 in bovine meat products in northern Italy. Int J Food Microbiol 90: 257-262, 2004.

94. Sutcliffe P, Picard L, Fortin B, Malaviarachchi D, Hohenadel J, O’Donnell B. Escherichia coli O157:H7 outbreak at a summer hockey camp, Sudbury, 2004. CCDR 30-22, 2004.

95. Taege A. The Cleveland Clinic. Disease Management Project. Medicine Index. Infectious Diseases. Food-borne disease. February 2004. Disponível em: http://www.clevelandclinicmeded.com/ diseasemanagement/infectiousdisease/foodborne/foodborne.htm. Acesso em: 4 fev. 2006.

96. Tauxe RV. Emerging foodborne pathogens. Int J Food Microbiol 78:31-41, 2002.

97. Tavares TM, Serafini AB. Avaliação microbiológica de hambúrgueres de carne bovina comercializados em sanduicherias tipo "trailers" em Goiânia, GO. Rev Patol Trop 32: 46-52, 2003.

98. Tavechio AT, Ghilardi ACR, Peresi JTM, Fuzihara TO, Yonamine EK, Jakabi M, Fernandes SA. Salmonella serotypes isolated from nonhuman sources in São Paulo, Brazil, from 1996 through 2000. J Food Prot 65: 1041-1044, 2002.

99. United States General Accounting Office (GAO). Report \#01-973. Food Safety Surveillance Systems, September 2001. Disponível em: http://www.gao.gov/new.items/d01973.pdf. Acesso em: 8 set. 2005.

100.United States Department of Agriculture (USDA). Economic Research Service (ERS). Briefing room. Economics of foodborne disease: Salmonella. April 21, 2003. Disponível em: http://www.ers. usda.gov/briefing/FoodborneDisease/Salmonella/. Acesso em: 22 fev. 2006.

101.United States Department of Agriculture (USDA). Food Safety and Inspection Service (FSIS). News $\&$ Events. News Releases. FSIS ground beef sampling shows substantial E. Coli O157:H7 decline in 2004. February 28, 2005. Disponível em: http://www.fsis.usda.gov/News_\&_Events/NR_022805_ 01/index.asp. Acesso em: 22 fev. 2006.

102. Unnevehr L, Roberts T, Custer C. New pathogen testing technologies and the market for food safety information. AgBioForum 7: 212-218, 2004.

103.Vugia D, Hadler J, Chaves S, Blythe D, Smith K, Cieslak P, Jones T, Cronquist A, Goldman D, Guzewich J, Angulo F, Griffin P, Tauxe R. Preliminary foodnet data on the incidence of foodborne illness - selected sites, United States, 2002. MMWR 52: 340-343 , 2003. 
104.Walls I, Scott VN. Use predictive microbiology in microbial food safety risk assessment. Int J Food Microbiol 36: 97-102, 1997.

105.Watkins AE, Marks BP. A combined convection cooking and Salmonella inactivation model for ground meat and poultry patties. ASAE Annual Meeting, paper number 026046, 2002.

106.Wen Q, McClane BA. Detection of enterotoxigenic Clostridium perfringens type A isolates in american retail foods. Appl Environ Microbiol 70: 2685-2691, 2004.

107.World Health Organization (WHO). Food Agriculture Organization (FAO). Recommended International Code Of Hygienic Practice For Processed Meat And Poultry Products - CAC/RCP 13 - 1976, Rev.1. 1985.

108.Zansky S, Wallace B, Schoonmaker-Bopp D, Smith P, Ramsey F, Painter J, Gupta A, Kalluri P, Noviello S. Outbreak of Multidrug-Resistant Salmonella Newport - United States, January-April 2002. MMWR 51: 545-548, 2002.

109.World Health Organization (WHO). WHO Media Centre. Fact Sheet $\mathrm{N}^{\circ} 237$. Food safety and foodborne illness. January 2002. Disponível em: http://www.who.int/mediacentre/factsheets/fs237/ en/. Acesso em: 04 de fevereiro de 2006. 


\section{PRÓXIMOS EVENTOS NAÁREA DE PATOLOGIA TROPICALE SAÚDE PÚBLICA}

Kinetoplastid diseases 2006. Dakar, Senegal, 11th to 15th march 2006. Information: $\mathrm{http}: / /$ mangosee.com/mangosteen/kinetoplastids2006

I Congreso Panamericano de Zoonosis. V Congreso Argentino de Zoonosis. La Plata, Argentina, 10 a 12 de maio de 2006. Informações: E-mail: nildarad@yahoo.com.ar ou info@zoonosis2006.com (mais informações na página 58 deste número).

III Simpósio Internacional de vigilancia y lucha antivectorial. Varadero, Cuba, 23 a 25 de maio de 2006. Informações: E-mail: bisset@ipk.sld.cu

XV Reunión de la Comisión Intergubernamental del Cono Sur para la Eliminación de Triatoma infestans y la Interrupción de la Transmisión de la Tripanosomiasis Transfusional y Renovación del Curso de Diagnóstico, Manejo y Tratamiento de Enfermedad de Chagas. Organización Panamericana de la Salud y Médicos Sin Fronteras. Brasília, DF, 6 a 9 de junio de 2006. Informações: E-mail: salavater@uru. ops-oms.org

I Simpósio de Atualização em Infectologia do Paraná. Curitiba, PR, 9 e 10 de junho de 2006. Informações: E-mail: queiroz.telles@uol.com.br

12th International Congress on Infectious diseases. Lisboa, Portugal, 15 a 18 de junho de 2006. E-mail: info@isid.org

11th International Congress of Parasitology (ICOPA XI), Glasgow, Reino Unido, 6 a 11 de agosto de 2006. Informações: www.icopaxi.org

XVI International AIDS Conference (AIDS 2006). Toronto, Canadá, 13 a 18 de agosto de 2006. Informações: info@aids2006.org

$11^{\circ}$ Congresso Mundial de Saúde Pública e $8^{\circ}$ Congresso Brasileiro de Saúde Coletiva. Rio de Janeiro, RJ, 21 a 25 de agosto de 2006. Informações: www.wfphacongress06.com

$14^{\circ}$. Congresso Brasileiro de Parasitologia Veterinária e $2^{\circ}$ Simpósio LatinoAmericano de Rickettsioses. Ribeirão Preto, SP, 3 a 6 de setembro de 2006. Informações: www.cbpv.com.br/congresso

X Congresso Brasileiro de Controle de Infecção e Epidemiologia Hospitalar. PortoAlegre, RS, 11 a 15 de setembro de 2006. Informações: E-mail: inscriçoes@abev.com.br

XXII Reunião Anual de Pesquisa Aplicada em Doença de Chagas e Leishmanioses. Uberaba, MG, de 20 a 22 de outubro de 2006. Informações: E-mail: reuniaouberaba@mednet.com.br

XLIII Congresso da Sociedade Brasileira de Medicina Tropical, Campos do Jordão, SP, 11 a 15 de março de 2007. Informações: www.sbmt.org.br 